\title{
Efetivação das políticas curriculares desenvolvidas pelo grupo escolar Lauro Sodré e seus desdobramentos sobre os processos formativos (1968 a 2008)
}

\author{
Renato Pinheiro da Costa*
}

renatopc@ufpa.br

\section{Paulo Sérgio de Almeida Corrêa**}

paulosac@ufpa.br

\begin{abstract}
Resumo
A presente investigação teve como objetivo analisar as repercussões das reformas educacionais no trabalho docente e no processo ensino-aprendizagem desenvolvido no espaço do Grupo Escolar Lauro Sodré, refletindo sobre sua organização curricular em face da política governamental de expansão do sistema de ensino no estado do Pará. Foi desenvolvida a partir da problemática: quais eram as prescrições para o exercício do trabalho docente e como se efetivaram as práticas curriculares desses sujeitos nessa instituição? O período histórico da investigação foram os anos de 1968 a 2008, a fonte de investigação foram as narrativas de ex-gestores e ex-professores da instituição, que nos levou a concluir que o Grupo Escolar esteve alinhado às políticas curriculares de formação para a cidadania, entretanto se mostrou como espaço de relações, tensões e conflitos, sobretudo para que os princípios democráticos e participativos fossem considerados no processo educacional da instituição.
\end{abstract}

\section{Palavra-chave}

Educação; Grupo Escolar; Trabalho docente

\section{Effectiveness of the curricular policies developed by the school group Lauro Sodré and its unfolding on the formative processes}

\begin{abstract}
This research aimed to analyze the impact of educational reforms in the teaching profession and the teaching-learning process developed within the School Group Lauro Sodre, reflecting on his curriculum organization in the face of government policy of expansion of the education system in the state of Pará. It was developed from the issue: what were the requirements for the exercise of the teaching profession and as been affected curricular practices of these subjects at this institution? The historical period of investigation were the years 1968-2008, the source of investigation were the narratives of former managers and former teachers of the institution, which led us to conclude that the School Group has been aligned with the curriculum of training for citizenship policies however it showed how space relations, tensions and conflicts, especially for the democratic and participatory principles were considered in the educational process of the institution.
\end{abstract}

\section{Keywords}

Education; School group; Job teacher

\footnotetext{
*Universidade Federal do Pará, Campus Universitário de Altamira. Líder do Grupo de Pesquisa: Grupo de Estudos e Pesquisas em História, Sociedade e Educação no Brasil-HISTEDBR/SECÇÃO ALTAMIRA-PA.

**Universidade Federal do Pará, Centro de Educação, Programa de Pós-graduação em Educação.
} 


\section{Introdução}

Em vista de prosseguir na investigação sobre a implantação dos Grupos Escolares ${ }^{1}$ no Estado do Pará, unidades de ensino criadas no início da república como projeto para disseminação do ensino, este trabalho foi produzido, dando atenção às narrativas de profissionais que atuaram no Grupo Escolar Lauro Sodré no Município de Moju², Estado do Pará, e assim trazendo elementos para a reflexão no contexto da história das instituições escolares, sobre a importância e a implicação que os Grupos Escolares tiveram para o processo de forção da população em um contexto mais amplo.

Esta produção está situada no ambiente social do Município de Moju, interior do Estado do Pará, com a categoria profissional de ex-servidores públicos. Desse modo, a investigação está fundamentada na abordagem da "Nova História", tomando como aporte teórico Peter Burke, por apresentar uma leitura detalhada das diferenças entre a abordagem tradicional e a Escola dos Annales no registro da história, determinando as falas dos sujeitos sociais como essenciais para esse processo, caracterizada como: "história vista de baixo, em outras palavras, com a opinião das pessoas comuns e com sua experiência da mudança social”. (BURKE, 1992, p. 13)

Os dados oficiais determinam que o Grupo Escolar Lauro Sodré da cidade de Moju foi criado pelo Decreto Estadual no 1443 de 09 de julho de 1907. Seu edifício contava com uma estrutura predial de apenas um pavimento, com sala da direção, secretaria, duas salas de aula, uma copa, banheiros feminino e masculino. Era uma estrutura simples se comparados a de outras instituições do mesmo gênero de outras cidades, que eram bem mais suntuosas, mas, para a sociedade local, teve um enorme impacto na dinâmica da organização da cidade e da vida da população. Em 1968, a instituição escolar mudou de endereço para um outro prédio construído sob a orientação do projeto “Aliança para o Progresso", , com uma estrutura maior e adequado às demandas dos projetos arquitetônicos dos novos padrões de prédios escolares da época.

Para a realização deste trabalho, alguns passos metodológicos tiveram que ser atendidos para concentrar o foco no objeto de investigação e, ao mesmo tempo, estar mais concentrado no problema de pesquisa. Destarte, o lapso temporal está determinado entre os anos de 1968 a 2008, por ser um período demarcado pela mudança predial da instituição e a implementação de políticas educacionais determinantes para a atividade docente. Desse modo, vale a pena destacar que, embora em 1971 a nomenclatura Grupo Escolar tenha sido mudada com a Lei de Diretrizes e Bases da Educação 5.692/71, mesmo assim, levou-se muito tempo para que a população se adaptasse a essa mudança conceitual, fato evidenciado na narrativa dos entrevistados. De outra forma, preservamos a nomenclatura "Grupo Escolar", para manter um padrão de linguagem que identificasse a política educacional do período histórico que teve imensa repercussão no processo educacional até o início do século XXI.

Como fonte de investigação foram priorizadas as narrativas de ex-gestores e ex-professores que estudaram e trabalharam na referida instituição, pois, como ressalta Oliveira (2005, p. 94): “A história oral recupera aspectos individuais de cada sujeito, mas ao mesmo tempo ativa uma memória coletiva, pois, à medida que

\footnotetext{
${ }^{1}$ No Estado do Pará segundo Estácio e Nicida (2016, p. 359) destacam que o primeiro Grupo Escolar foi criado na cidade de Alenquer em 1899.

${ }^{2}$ É importante ressaltar que este é o quarto capítulo da dissertação: O Grupo Escolar Lauro Sodré em face da política de expansão do sistema escolar no Estado do Pará: Institucionalização, organização curricular e trabalho docente (1968-2008).

${ }^{3}$ Programa cooperativo de iniciativa dos Estados Unidos, nasceu em 1961 com o intuito de acelerar o desenvolvimento social da América Latina.
} 
cada indivíduo conta sua história, esta se mostra envolvida em um contexto sócio-histórico que deve ser considerado". Com isso, optamos pela entrevista semiestruturada como técnica para a coleta de dados, a fim de deixar os entrevistados mais à vontade para narrar suas vivências.

Com a aplicação dos critérios de seleção para a escolha dos sujeitos, visando à aplicação da entrevista, foram identificados 3 ex-diretores e 6 ex-professores, um quantitativo julgado adequado para subsidiar a elucidação do problema de pesquisa proposto nesta parte do estudo. Desse modo os entrevistados são: EXGESTORES: Raimundo Roberto Almeida Ribeiro, Maria Augusta Nery Cristo e Ivone Fernandes da Silva; EX-PROFESSORES: Maria de Fátima Maia Nery, Maria Auxiliadora e Silva da Silva, Regina Cardoso Nery, Maria Antônia Araújo Gordo e Nadir Trindade da $\mathrm{Cu}-$ nha.

\section{Perfil dos gestores e professores entrevistados}

Os gestores selecionados para este trabalho de pesquisa através de seus relatos puderam compartilhar as experiências que vivenciaram quando à frente da instituição de ensino Lauro Sodré. Nesse sentido, é válido mostrar o perfil que cada um apresenta, posto, que segundo Lombardi e Nascimento. (2004), pelo apanhado da "Nova História", as fontes históricas também estão nas narrativas orais e nas memórias das pessoas que participaram do processo de construção da escola.

As lembranças dos ex-servidores a respeito do período em que estiveram à frente da instituição escolar é muito mais do que uma simples visita aos trabalhos que realizaram no passado, é uma expressão forte da organização e estrutura do ensino, da política educacional, da organização docente, da forma de gestão. Um apanhado geral do conjunto social, que somente pode ser acessado pela memória que, para Le Goff (1990, p. 473), está ligada à psicologia social e à medida que são provocadas: “[...] à medida que esta memória está ligada aos comportamentos, as mentalidades, novo objeto da nova história, traz a sua colaboração". Ou seja, a narrativa dos entrevistados contribui para a composição da conjuntura educacional em que os Grupos Escolares estavam envolvidos.

No quesito que diz respeito à formação, os três ex-gestores mostraram que o percurso formativo trilhado por eles, começou pelo grupo escolar e teve continuidade em outro município, pois, em Moju, o ensino era de $1^{\mathrm{a}}$ até a $5^{\mathrm{a}}$ série do primário. Mas todos conseguiram concluir o nível primário, depois nível secundário, em seguida, a graduação e apenas um cursou uma pósgraduação.

O período de formação, tanto primária quanto secundária e superior dos entrevistados, varia entre $\mathrm{o}$ final da década de 1960 e início da década de 1990, indicando a contemporaneidade das formações, muito embora depois de saídos do Grupo Escolar Lauro Sodré tenham ingressado em instituições de ensino diferentes, a base curricular da formação deles era idêntica por se tratar de uma base nacional comum de ensino regulamentada pela Lei de Diretrizes e Bases da Educação LDB 4.024/61 e, posteriormente, pela sua complementação LDB 5.692/61.

Embora seja evidenciado que os gestores já tinham o ensino superior quando estavam à frente da instituição, e isso pode ter sido um dos requisitos para assumirem a função, somente o Professor Raimundo Roberto Almeida Ribeiro cursou uma pós-graduação, pelo motivo de achar necessário ter preparação na área em que atuaria, como ressalta, dizendo: "Para mim foi uma experiência muito grande, por conta que eu tive que fazer até um curso de, uma pós-graduação de gestão, eu me sentia no dever de fazer um curso de gestão 
para que eu pudesse colaborar com a gestão do Lauro Sodré e automaticamente com os alunos". (RIBEIRO, 2010)

A expectativa do trabalho administrativo no estabelecimento de ensino fazia com que o diretor se mantivesse informado e por serem da área da educação e atuarem como docentes este profissional buscava outras formações, de modo a atender melhor ao público e desenvolver seu trabalho com eficácia, como esclareceu o Professor Raimundo Roberto Almeida Ribeiro em sua fala.

Com relação à assunção ao cargo da direção da escola, os gestores esclareceram que foram indicados para a função, pois esse era um cargo estratégico dentro das lutas sindical e política e o que essa função representa no município, devido a escola Lauro Sodré ser a escola sede da Secretaria Estadual de Educação - SEDUC do Estado do Pará, no Município de Moju. Desse modo, o processo de eleição direta para diretor não foi concretizado, muito embora o Professor Raimundo Roberto Almeida Ribeiro, depois de ser indicado para a função de diretor tenha realizado eleições na instituição e sido confirmado no cargo, teve que abdicar da função por conta das mudanças na estrutura do ensino no município.

Os docentes envolvidos nesta pesquisa que relatam seus perfis consideram o Grupo Escolar Lauro Sodré o lugar de base da formação que receberam, embora, também, pelas condições de ensino na cidade de Moju tenham sido obrigados a migrar para outros municípios, pois, como destaca Paro (1998), entre as décadas de 1970 e 1980, as condições em que ocorria o ensino não eram muito favoráveis para as pessoas oriundas das camadas menos favorecidas economicamente. Assim, no intuito de continuar o estudo ginasial e nível subsequente, os docentes mostraram que os fundamen- tos da formação que receberam eram frágeis e apenas serviram de suporte para o profissionalismo.

Eu estudei o ensino primário do Lauro Sodré, só de primeira a quinta, lá só tinha o primário, depois fui para Belém estudar.

Estudei em Belém até o segundo ano do ginásio, depois vim para Moju e continuei trabalhando, aí, sim, fui estudar em Abaetetuba e fiz o terceiro e quarto ano ginasial em Abaetetuba e foi lá que eu terminei meu magistério. Em Abaetetuba fiz o terceiro e quarto curso ano ginasial e depois terminei o primeiro, segundo e terceiro ano magistério, era educação, naquele tempo era curso de educação que correspondia ao magistério (NERY, 2010)

O regresso desses estudantes à antiga instituição se deve ao fato de que, com o avanço nos investimentos em educação, em Moju, a partir do ano de 1977, ocorreu a instituição do ensino primário de $5^{\mathrm{a}}$ a $8^{\mathrm{a}}$ séries e depois, já no início da década de 1980, também iniciou o ensino secundário por módulos ofertado pela SEDUC.

A criação de mais escolas e vontade política de investir no avanço educacional por parte do governo do Estado movimentou o sistema de ensino local. Assim, a possibilidade de formação docente melhorou significativamente, dando oportunidade ao ingresso de novos profissionais no setor, que até então eram contratados segundo os critérios da direção da escola e ou indicação política.

\section{Quanto aos aspectos administrativo- pedagógicos do grupo escolar}

Os gestores entrevistados, ao responderem a esta questão, apresentaram a organização da instituição na gestão deles. Em todas as gestões, a escola contou com um corpo administrativo, técnico e docente atuante, também a participação da comunidade em todos os 
momentos da vida da instituição foi ressaltada, como forma de dizer que, embora o processo de escolha do gestor fosse por determinação da conveniência política, mas pretendia-se que os desígnios democráticos fossem garantidos no processo administrativo.

A criação do Conselho Escolar 1999 tornou a instituição Lauro Sodré mais participativa, conforme ressaltava o professor Ribeiro (2010):

O Conselho tinha participação da administração, né, da gestão, tinha também representante dos pais, tinha representante dos professores, dos alunos, representante... inclusive da comunidade em torno, do Sindicato dos Trabalhadores Rurais na época, eram representante, por estarem muito próximo da escola, representante do corpo técnico administrativo, dos funcionários. Tudo passava pelo Conselho, desde as questões financeiras..., tudo, tudo, até as questões administrativas.

A opção pela abertura da participação da comunidade escolar nas decisões da escola fez com que organizações como Conselho de Classe e Conselho Escolar fossem criadas em 1999, dando prosseguimento à prática da gestão participativa desenvolvida pela Irmã Cecília Petrine quando esteve à frente da escola em 1977, que constantemente reunia os professores e membros da categoria dos alunos para decidir e encaminhar os eventos da instituição, segundo registro no livro ata das reuniões Moju (1977).

A opinião dos professores com relação ao funcionamento da instituição coincide com a descrição emitida pelos gestores ao relatarem sobre a participação e empenho da comunidade nas atividades institucionais, o que confirma a existência de organização por catego- rias na instituição e que estas estavam presentes na manutenção do sistema de ensino interno.

Em termos de organização, os docentes lembram a estrutura criada ao longo da história do Grupo para atender à demanda de alunos de idades variadas nas séries primárias. Nesse sentido Nery (2010) recorda:

\begin{abstract}
Antes de 77 tinha de dia de $1^{a}$ a $5^{a}$ séries nos três turnos de dia e a noite tinha assim umas aulas, que eu ainda fui professora, que é a $1^{a}, 2^{a}, 3^{a}$ e $4^{a}$ séries que não era o supletivo no início, no início..., era para quem não tinha o MOBRAL ${ }^{4}$ nessa época, ... era a primeira, era só para desemburrar o pessoal, era só para alfabetizar, Movimento Brasileiro de Alfabetização, MOBRAL, não é! Era só para alfabetizar, era à noite, era sempre à noite o MOBRAL, depois do MOBRAL que veio, foi implantado o ensino supletivo junto com o ensino fundamental, que ainda não era fundamental, era primeiro grau. Ai depois dessa época foi implantado o primário completo aqui no Moju por meio da Irmã Cecilia Petrina de Carvalho que era uma freira da Congregação São José.
\end{abstract}

A descrição da professora reconstrói fragmentos do cenário operacional do Grupo Escolar que, seguindo as diretrizes do sistema de ensino com aulas em três turnos, atendendo aos alunos no nível de formação primária no modo regular e acelerado através do MOBRAL ou Supletivo, emitindo documentos, manteve a estrutura institucional funcionando mesmo em tempos difíceis ou com condições adversas.

\footnotetext{
${ }^{4}$ Segundo Bello (1993) o MOBRAL - Movimento Brasileiro de Alfabetização, foi criado pela lei 5.379/67, propondo a alfabetização funcional dos jovens e adultos visando "conduzir a pessoa humana (sic) a adquirir técnicas de leitura, escrita e cálculo como meio de integrá-la a sua comunidade, permitindo melhores condições de vida". Sua finalidade estava ligada ao prosseguimento das campanhas de alfabetização de adultos iniciadas com Lourenço Filho. Para o autor a preocupação do movimento era ensinar os alunos a ler e escrever.
} 
Preocupação institucional em relação ao preparo do professor para o exercício de suas práticas educativas

Em meio às demandas pedagógicas, a necessidade da formação continuada era um quesito importante que o gestor considerava no desempenho de sua função, e embora, em princípio, seja do interesse do docente buscar meios para estar constantemente atualizando-se nos métodos e processos pedagógicos, nos cursos de aperfeiçoamento e de formação continuada, mesmo assim o diretor da instituição de ensino fica atento às dificuldades e oportunidades de melhoria da qualificação do quadro de educadores da instituição. Nesse sentido, a temática a respeito da preocupação do gestor para com o preparo do professor para o exercício de suas práticas educativas não se refere somente se o diretor esteve interessado em encontrar cursos de qualificação para o docente, mas se ele estava atento aos problemas que este enfrentava no dia a dia do processo ensinoaprendizagem.

Na visão dos docentes, os momentos de formação que ocorriam no interior do Grupo Escolar eram essenciais no repasse de informações importantes para auxiliar no preparo do plano de aula e execução das tarefas educacionais. Foram expostos nos relatos, que a oferta de cursos de aperfeiçoamentos ofertados via SEDUC era constante, posto que o nível de qualificação dos docentes na maioria ainda era precário, por exemplo, para os docentes ministrarem aula no ensino de $5^{\mathrm{a}}$ a $8^{\mathrm{a}}$ série segundo relato da professora Maria Auxiliadora.

O interesse de qualificação dos docentes para atuar nas séries mais elevadas do ensino primário era uma das finalidades dos cursos promovidos pelo Centro de Treinamento de Recursos Humanos da Secretaria Estadual de Educação. Contudo, além dessa, havia outras carência na formação dos docentes em outras séries e áreas que demandavam a intervenção do Estado mediante oferta de estudos da área, como no caso do nível da alfabetização em que os professores recebiam formação específica como consta no relato de Gordo (2010):

Quando eu trabalhei eu participei de um curso em Abaetetuba e depois outro em Belém, mas não foi para todos, foi só para cinco professores, que era um curso do CEBS, que era o Centro de Educação Básica, onde eu trabalhei com duas turmas no Lauro Sodré e só deixei depois que eu fui para a Escola Maria da Conceição. Era na época do Helio Gueiros, ai ele mandou gradear todas as salas do Lauro Sodré, do Antônio de Oliveira Gordo e da Ernestina, ai tinha duas salas da escola que eles equiparam só com o material da CEBS que era uma sala de aula para atender todas as crianças, não era para crianças especiais, mas era para ser para as crianças mais carentes só que numa cidade que nem Moju naquela época todo mundo era carente e ai era dado todo material para as crianças, $t i-$ nha brinquedo, tinha papel, cadernos, canetas, lápis, giz de cera, mesinhas, mesa do professor, armários para guardar os materiais..., tudo acabou.

Essa era uma formação para os professores que iam trabalhar com essas turmas, assim como tinha a formação para os professores que iriam trabalhar com crianças especiais, neste caso os professores foram a Oneide, Eloadir, Rosalina e a Belém, eram quatro professores.

A estrutura montada pelo Estado, através do Departamento de Recursos Humanos da Secretaria Estadual de Educação, integrava a agenda de uma política de expansão do ensino primário em todo o Estado, por isso havia a necessidade de qualificar a mão-de-obra docente a fim de habilitá-los ao trabalho com as séries do ensino primário e nos programas desenvolvidos na instituição, como foi o caso do Centro de Educação Básica - CEB que a escola Lauro Sodré abrigou. 


\section{Regulamentação oficial que orientava - trabalho docente e os processos educativos}

A regulamentação do ensino por meio das legislações oficiais tornava a instituição educacional um ambiente de seriedade com o trato nas questões profissionais e organização do tempo institucional, mas também essa era uma ferramenta de reivindicação de garantias de melhorias para o exercício da profissão.

Os relatos dos docentes embora rememorem a existência das Leis de Diretrizes e Bases da Educação 5.692/71 e 9.394/96, afirmaram que não se recorria a essa legislação, pois, na época em que a escola Lauro Sodré era do Estado vigorava o manual conhecido como regulamento da SEDUC. Após a municipalização do ensino, a educação começou a ser orientada além da LDB pelo Regime Jurídico Único de Moju, como ressalta a Augusta (2010): “em relação ao município", somente a Lei Orgânica do Município, nela tinha algumas coisas. A municipalização deixou tudo mais próximo e a gente não tinha dessa de depender tanto de SEDUC".

A lembrança manifestada na fala da gestora mostra que as instâncias da educação nos âmbitos federal, estadual e municipal eram organizadas no sentido de ter seu sistema educacional amparado pelas regulamentações oficiais. E sendo competência dos Estados e municípios a administração de seus respectivos sistemas de ensino, no Pará, a SEDUC e, em Moju, a Secretaria Municipal de Educação. Amparados na lei maior do setor, a LDB, fizeram suas adaptações do texto legal tornando o ensino mais próximo da realidade.

Além do recurso da lei, outra forma de regulamentar o funcionamento da escola ressaltada pela ges- tora Ivone Fernandes, foi a elaboração do Projeto Político Pedagógico - PPP, que fazendo parte do processo descentralizador da gestão, estava amparado pela legislação como meio de desenvolvimento do trabalho administrativo.

Para os professores, contudo, pela condição de funcionário e pela mobilização de organização da categoria, outra legislação essencial era o Estatuto do Servidor Público ${ }^{6}$, que amparava o servidor em muitas situações de perseguição no desenvolvimento de sua função.

Legislação?!

Tinha sim!

Tinha!

Tudo era regulado, amparado pela lei.

Com certeza, tudo baseado na lei do funcionalismo público, que nessa época já tinha uma lei própria, como aconteceu com o caso daquela professora que foi demitida e era efetivada e não podia, era a lei, se ela fosse contratada não tinha jeito, mas como ela já tinha sido efetiva$d a$, tinha decreto, esse decreto de nomeação até 5 anos podiam fazer o que quisessem com o funcionário, mas depois dos cinco anos não podia, era uma lei. Depois de cinco anos de você trabalhando no Estado você já era amparado, você já era efetivado, ai já vinha um decreto para você e você já estava efetivo para sempre. Ninguém podia fazer nada, ninguém, podia transferir, podia..., mas botar na rua não podia.

Para você fazer uma ideia a Ernestina Pereira Maia, a minha mãe ela foi perseguida por esse mesmo prefeito que me perseguiu, então a mamãe ela era professora e ele trouxe uma inspetora tradicional para cá, uma pessoa poderosa, então a mamãe era do outro lado e a mamãe era tinhosa também. E ai ele disse que iria mandar a mamãe para a escola de origem dela, a Escola Paissandu, mas ela não foi nesta escola. Aí ela foi para Belém e falou com o sogro do governador que era amigo dela e aí foi ele foi com o

\footnotetext{
${ }^{5}$ A referência que a professora faz a legislação municipal se deve ao fato de em 2001 o ensino de Moju ter sido municipalizado, e muitas das diretrizes da organização do setor passou a ser de competência da Lei Orgânica do Município.

${ }^{6} \mathrm{O}$ documento que a docente se refere deve ser O Estatuto do Magistério Público Estadual do Pará Lei ${ }^{\circ}$ 5351/86.
} 
Alacide e mandou bater uma portaria e deu para ela e disse Ernestina não vai trabalhar, fica na tua, vamos ver em que bicho vai dar, o dia que o inspetor te procurar ai tu vais mostrar a portaria para ele. Um dia veio a ordem para ela ir, as outras todas foram, coitadas não estavam respaldadas com nada, a dona Guilhermina que morava perto de minha casa, colocaram num caminhão velho chamado "Velha Boia" e foi para o Ateua-Grande, a mamãe tinha que ir lá para o Ubá, ai mandaram chamar a dona Ernestina e ela disse: Estou aqui, o que desejam de mim. Ele disse a senhora vá se arrumar, a senhora vai assumir agora essa escola lá no Paissandu, o inspetor da SEDUC está aqui e ele veio para lhe reconduzir para lá. E ela respondeu: Olhe eu poderia até ir, se esta ... não valesse nada. Ai ele leu e viu a assinatura do governador, e ela disse estão pensando que sou carneiro, não sou carneiro não.

Isso quer dizer que além da regulamentação do Estado tinha também o Estatuto do Servidor Público que servia para organizar. (NERY, 2010)

A legislação educacional e o Estatuto do Servidor Público eram os apoios que os docentes do Grupo Escolar Lauro Sodré tinham para se resguardar nas articulações feitas por forças externas, ou, como em outros casos, para exigir que seus direitos fossem respeitados. Nesse sentido, o próprio sindicato da categoria promovia cursos sobre a utilização da legislação a fim de conscientizar os associados de seus direitos.

A discussão sobre as leis já começou mais quando começamos a entrar no sindicato e a gente ia nos cursos, porque na época não era SINTEP ${ }^{7}$ era a FEPPEP ${ }^{8}$ e tinha cursos, esses cursos regional tinham palestras e tinham os cursos para professores, a gente da primeira série ia se aperfeiçoar, ai vinham professores do que hoje é SINTEP traziam pessoas para fazer palestra sobre as leis, ai a gente já aprendia lá. O sindicato foi quem iniciou isso, ele tinha influência nessa área, nesse tempo o sindicato foi quem abriu nossos olhos, eles diziam: "Olhem isso aqui não é bom... "E a gente discutia, ai vinha o Miriquinho, era o Edmilson e outros, todo mundo era contra a municipalização, já se falava de municipalização ha muitos anos atrás e vieram municipalizar agora em 2001. (AUXILIADORA, 2010)

A organização sindical foi de grande auxilio para que os educadores conseguissem garantir os direitos trabalhistas e boas condições para o desenvolvimento de sua atividade docente. A opção por organizar a categoria através da formação e com isso sensibilizá-los para participação nas atividades sindicais, gerou a conscientização de vigilância com relação às condições de trabalho e relações trabalhistas.

\section{A organização da proposta curricular destinada à formação educativa}

No bojo da discussão da organização do sistema de ensino, a questão curricular não pode ser deixada de fora das análises, pois esse é um requisito que diz respeito ao fluxo das disciplinas, ao conteúdo programático, ao tipo de estrutura criada para o desenvolvimento do trabalho educacional.

O direcionamento que a escola dava à composição do currículo que era trabalhado pelos professores em sala de aula, reflete o compromisso da instituição com o ensino e, consequentemente, com o processo de escolarização dos educandos.

$\mathrm{Na}$ escola Lauro Sodré esse compromisso, ao que tudo indica, pelo depoimento dos gestores, representou uma das marcas da organização democrática da

\footnotetext{
${ }^{7}$ Sindicato dos Trabalhadores da Educação Pública.

${ }^{8}$ FEPPEP - Federação dos Profissionais da Educação Pública do Pará. A organização sindical dos profissionais da educação do Estado do Pará surgiu durante a década de 1970 com a criação da APEPA - Associação de Professores do Estado do Pará, que em 1985 ampliou sua organização passando a incorporar em sua estrutura todos os servidores e técnicos da educação transformando-se em FEPPEP.
} 
instituição, pois, embora o Ministério da Educação, todos os anos, enviasse o conteúdo a ser trabalhado nas disciplinas do ensino primário, mesmo assim, depois de percorrer setores como Secretaria Estadual de Educação - SEDUC/Pará e Secretaria Municipal de Educação SEMED/Moju, ao chegar à escola, esse conteúdo sempre era revisto e readaptado nas reuniões pedagógicas no início de cada ano letivo.

Antes, quando o ensino primário era de responsabilidade do Estado, a escola recebia o conteúdo via Unidade Regional de Ensino - URE, tal como extraiu de suas memórias o professor Ribeiro (2010):

Essa questão curricular, nós tínhamos uma proposta da SEDUC que vinha lá de cima, a secretaria mandava para a URE e a URE nos enviava, enviava para a escola, ai nós só fazíamos aqui o nosso planejamento com alguns técnicos que nós tínhamos aqui mesmo e fazíamos nosso planejamento baseado no currículo educacional do Estado que era da SEDUC fazendo algumas adaptações aqui na nossa escola de acordo com a nossa realidade de acordo com a nossa cultura, inclusive, por exemplo, a parte do cronograma da escola era todo baseado na nossa cultura, na época era a festa do Divino e a gente também colocava no calendário. Com todo cuidado para fazer essa parte curricular baseado na cultura do municipio. Sempre foi feito assim, acredito que até hoje é feito dessa forma aqui no Moju.

Já se preocupava com o Círio do Divino, Festa de Nazaré, Feira de Arte, até a parte na época, o negócio da cultura do pessoal do interior na época da pimenta do reino, da safra... a gente se preocupava nessa época, era mês de agosto, fazia adaptação porque o aluno faltava muito nessa época, morava na zona rural e tinha que apanhar pimenta.

Acredito que hoje ainda é feito também dessa forma.

Pelo fio narrativo que o professor construiu a respeito do assunto, é destacado que o currículo escolar, embora tivesse o caráter oficial, sua estrutura era flexível, pois, possibilitava a incorporação ao seu conteúdo de temas regionais, ou envolvendo a cultura local, o que por sua vez fazia com que o calendário escolar fosse reorientado, pois, a composição dos dias letivos prescritos pelos setores hierárquicos superiores, não considerava as condições sociais e culturais dos estudantes moradores da zona rural.

Com a discussão visando à aproximação do currículo à realidade do estudante, foi possível adequar o calendário escolar ao cotidiano da comunidade, pois, como destaca Azanha (1991, p. 1), uma das vantagens da municipalização do ensino seria a possibilitar o currículo escolar refletir a cultura local.

A partir da municipalização do ensino a contextualização curricular ficou mais próxima da realidade da instituição de ensino, mesmo sendo seu arcabouço originário de instâncias longínquas. Nesse sentido, a professora Augusta (2010), ao consultar suas memórias, relata:

Com relação ao currículo ele tinha por base o de lá da SEDUC, e aí ele era discutido com a coordenação pedagógica, diretor..., na reunião de planejamento semestral com a própria comunidade era discutido para que o professor não levasse aquilo prontinho da SEDUC, mas graças a Deus a gente colocou nessa época muito curso para convencer o professor para discutir aquele planejamento, todo tempo encorajando, mas tinham professores que não queriam discutir eu lembro bem de alguns que eram bem resistentes a discussão, mas como vieram professores muito bons de Abaetetuba como o professor de letras o Maçalino, tinha outro de matemática também, eles, sabe, trouxeram um proposta curricular, sabe...boa, e foi nessa época da interdisciplinaridade e eles foram fundamentais nesse processo, de Belém também o Andreson, e ai nós tínhamos todos conosco graças a Deus..., a Regina também que era formada, que tinha conhecimento grande em Estudos Paraenses.

Para o currículo escolar ganhar forma na condição de municipalizada em que a escola Lauro Sodré 
se encontrava, foram muitos os desafios enfrentados, pois havia resistências de docentes que não queriam participar da readaptação curricular. Com o investimento em cursos tratando da importância da participação na organização desse artefato cultural, a escola conseguiu superar essa dificuldade.

As atividades curriculares da escola eram desenvolvidas mediante a proposta que o sistema de ensino traçava, ou seja, o currículo ajudava a reforçar as ideologias predominantes e afirmar conceitos morais vigentes na sociedade, como sugere SILVA (2010, p. 31) ao dizer que: "A escola atua ideologicamente através do currículo $[\ldots] "$ ".

Para o autor, as disciplinas do currículo escolar abordam direta ou indiretamente na formação ideológica do educando. E pelo depoimento dos docentes os componentes disciplinares ministrados no ensino fundamental objetivavam justamente a modelagem da mente das crianças, jovens e adultos.

Na primeira a quarta eu dava aula de português, matemática, estudo sociais e ciências, era um professor por série para quatro disciplinas, às vezes eu dava até $9 h$ português, e depois eu colocava um pouco de matemática ou ciências, variava nos dias, tudo dentro de uma organização, tinha que fazer o calendário.

Na sexta-feira era dia de dar aula de religião, era para ensinar as criancinhas a rezar. Naquele tempo não tinha crente era só católico aí a gente deitava e rolava. Depois, nesse mesmo dia, tinha que fazer recreação com eles na própria sala de aula, fazer brincadeiras com eles na sala de aula, para não ficar só aquele negócio parado, para a criança ficar mais. (NERY, 2010)

$\mathrm{O}$ relato do desenvolvimento das atividades dos dias da semana já mostra que havia uma organização que os estudantes seguiam, já sendo iniciados no cumprimento de regas e aceitação das determinações superiores.

\section{Aspectos concernentes à infraestrutura didático-pedagógica para auxiliar - desenvolvimento do trabalho educativo docente}

Devido ao fato de o prédio do Grupo Escolar pertencer ao Estado, as condições de infra-estrutura estavam ligadas aos investimento que a SEDUC fazia no edifício. Assim, desde a inauguração do prédio destinado ao funcionamento da Escola Lauro Sodré, os gestores travaram muitas batalhas para convencer de que havia a necessidade de ampliação do número de salas de aula, investimento na criação de espaços necessários para o bom desenvolvimento das atividades educacionais e aquisição de recursos que facilitassem o processo ensino-aprendizagem.

Ainda no final do século XX, as condições para o desenvolvimento do trabalho educacional eram insuficientes, segundo narrou o professor Ribeiro (2010) em seu testemunho:

A nossa ferramenta na escola Lauro Sodré que nós tínhamos na época era quadro e giz. O quadro negro na sala de aula, o giz e a quadra de esporte que nós tivemos porque foi um trabalho feito na época que eu estudava e os alunos construiram aquela quadra, foi construida pela comunidade.

Laboratório de informática não tínhamos, multimídia não tínhamos, computador na época não tínhamos, era máquina mesmo daquelas de datilografia.

Não tínhamos técnico pedagogo, nosso..., nossa..., me lembro que na época que nós tínhamos na época era eu diretor, dois vices diretores, a secretária da escola que me ajudava muito, saudosa finada Dilza e eu tinha um técnico de manhã, um de tarde e um de noite, técnico de secretaria, era auxiliar administrativo. Essa parte pedagógica era nós mesmos que fazíamos, nós professores que nos reuníamos para o planejamento e fazíamos essa organização.

Na época que eu estava a frente, nós implantamos algumas normas, conversamos com os pais, com os alunos, sobre a im- 
portância dos alunos colaborarem com as normas da escola, chegarem no horário, não estarem saindo da sala de aula para não prejudicar as outras aulas e a gente controlava bem..., bem, não excelente, mas de uma forma boa, de boa qualidade o controle

Nota-se que somente com a colaboração da comunidade foi que as carências em infraestrutura foram dribladas, pois, com a realização de eventos festivos, torneios e vendas de comidas, a escola Lauro Sodré pôde promover melhorias em sua infraestrutura, como ocorreu no caso da construção da quadra de esporte como relata o professor Raimundo Almeida e a aquisição da biblioteca segundo o pronunciamento da professora Maria Augusta.

Com a elevação do investimento da educação básica, através do Fundo de Manutenção e Desenvolvimento do Ensino Fundamental e de Valorização do Magistério - FUNDEF, e mais tarde com o Fundo de Manutenção e Desenvolvimento da Educação Básica e de Valorização dos Profissionais da Educação - FUNDEB, o município passou a dispor de recursos financeiros para melhorar o setor educacional, e mesmo o prédio da escola Lauro Sodré ainda pertencendo ao Estado, mas pela parceria existente a administração municipal auxiliou a instituição, segundo informou a atual gestora Ivone Fernandes.

A visão empreendedora dos governos federal, estadual e municipal fez com que chegassem à escola Lauro Sodré melhorias em sua infraestrutura didáticopedagógica, o que, com certeza, incentiva o docente à melhorar seu método de ensino, utilizando recursos de que antes não podia dispor.

No Grupo Escolar Lauro Sodré, denominado escola Lauro Sodré a partir de 1971, as condições para o trabalho do profissional da educação contava com o mínimo de infraestrutura. Os docentes relatam a exis- tência dos mobiliários como carteiras, mesas, lousa para escrever. Com relação à estrutura predial, os professores mencionavam que, no início dos anos 1970, a instituição desfrutava de cinco salas de aula, uma quadra para esporte, uma sala para secretaria, uma sala para a direção, dois banheiros masculinos e outro para o sexo feminino e copa. Com o aumento no número de matrículas, a administração municipal interveio construindo mais duas salas de aula.

Além da estrutura física do edifício, o grupo escolar contava com a cooperação dos profissionais dedicados aos trabalhos da instituição. Em momentos de festas cívicas, todos os membros da comunidade se uniam para a apresentação da escola, como no desfile do dia 7 de setembro em que as manifestações exigiam postura, sincronia nas coreografias, dedicação nos ensaios etc.

No dia a dia do Grupo, a figura do supervisor escolar se destacava por ser a pessoa que articulava as questões pedagógicas, o que, na atualidade, corresponde à função exercida pelo coordenador pedagógico, mediando o processo ensino-aprendizagem.

\section{Dos recursos didáticos utilizados pelos professores a fim de desenvolver os processos de ensino-aprendizagem junto aos alunos}

O desenvolvimento do processo ensinoaprendizagem dentro da instituição também diz respeito ao trabalho de gerenciamento do espaço escolar, assim sendo, o diretor é o facilitador que busca meios para que este processo seja efetivado.

Do gestor emanava a política que conduz os trabalhos da instituição de ensino, ou seja, se o administrador é preocupado com o fluxo do processo de ensino e, para favorecer esta ação, busca recursos didáticos, materiais, utensílios que proporcionem ao docente 
condições para ministrar sua aula. Esse gestor faz a instituição de ensino adotar as características de sua administração.

Mas, diante das condições existentes no tempo histórico em que cada gestor esteve à frente do Grupo Escolar, muitos puderam contar com recursos ou condições de adquirir certos benefícios financeiros que outros não puderam usufruir.

Nesse sentido, o gestor Raimundo Almeida faz relação dos limitados recursos que a escola contava, dando ênfase apenas aos recursos como giz, quadro, livro didático para as séries iniciais e apostilas produzidas pelos professores. A professora Maria Augusta acrescenta a esta lista itens como a voz do docente e poucos materiais como papel, cola, lápis de cor disponibilizado pela Secretaria Municipal de Educação.

Nós tínhamos na época uma espécie de um processo do programa do livro didático de $1^{a}$ a $4^{a}$ série, $5^{a}$ a $8^{a}$ séries não existia livros didáticos gratuitos pelo programa do governo federal, então o que nós utilizávamos era quadro, giz e cada professor utilizava seu material através de apostila, no quadro... era apostilamento e quadro somente (RIBEIRO, 2010)

Contando com o mínimo de material didático para ser disponibilizado para o professor ministrar sua aula, a direção da escola tentava conduzir a situação, administrando os poucos recursos públicos enviados pela Secretaria Estadual de Educação. Embora entendesses que não poderia haver grandes rendimentos sem investimento em materiais para auxiliar o trabalho do docente.

Para o diretor, os recursos didáticos eram materiais necessários para o trabalho do professor; na perspectiva do docente, os recursos didáticos assumem outra conotação, são o meio facilitador do ensino, um auxilio no processo ensino-aprendizagem.
Era essa visão que os docentes tinham dos recursos didáticos, por isso elaboravam meios para produzi-los, usando a criatividade, como relata a professora Trindade (2010).

Os materiais para dar aula era a gente mesmo quem fazia com palitos de fósforo, papel grosso, bolinha de papel para pregar nas figuras, cartazes também, pintura.

Se o professor quisesse fazer um bom trabalho ele tinha que se virar ele mesmo

As estratégias empregadas pelos docentes para ter material didático que auxiliasse seu trabalho e desse ao aluno condições de aprender eram trabalhosas, mas a criatividade e a vontade de abordar um assunto de forma diferenciada faziam o profissional dedicar o tempo extra para construir objetos pedagógicos para sua aula.

Tinha um professor que fazia o material didático na casa. Ele vinha da casa dele com o material montado.

Aquele professor mais esforçado, que não tinha preguiça ele fazia todinho, ele trazia o cartaz do que ele tinha que mostrar na aula, ele mandava fazer aqueles dadinhos, fazia cubinhos para a criançada aprender com maior facilidade. Tinha uma professora no Lauro Sodré chamada Marlene, toda a aula dela era com cartaz, ela ilustrava a aula, a sala dela era a ultima sala e era todinha decorada com cartazes.

Eu usava a musica e na sexta-feira nós usamos o dia para brincar com as crianças, era só uma aulinha ali o resto era todo recreativo para a criança relaxar um pouco. (TRINDADE, 2010)

Os elementos e materiais utilizados pelo professor para ministrar sua aula variavam de acordo com a criatividade de cada um, mas, mesmo com os poucos materiais disponíveis, os alunos conseguiam ter acesso ao saber.

\section{O grupo escolar e seus benefícios à educação municipal}


A organização do ensino primário em Moju começou antes da existência do Grupo Escolar, pois suas bases estão ainda no período imperial quando a educação acontecia em ambientes como as casas dos professores no sistema conhecido como escolas isoladas.

A partir do golpe revolucionário dos republicanos, o ensino primário assumiu outra configuração. $\mathrm{O}$ que ocorreu em Moju constituiu o resultado da política desenvolvimentista estruturada a partir do ensino e o Grupo Escolar tornou-se o símbolo dessa política.

Desse modo, o Grupo Escolar Lauro Sodré desde a sua fundação, tornou-se o marco da educação do município. Ele foi a primeira instituição de ensino, por isso, chegar ao centenário de sua existência é mostrar que houve bons resultados no seu trabalho, fato confirmado pelo testemunho da professora Fátima Nery ao afirmar que:

Os beneficios foram enormes, porque quando eu me entendi o Lauro Sodré já existia, que era o grupo escolar que era onde fica o FORUM hoje, minha primeira escola foi lá e depois, construiram o Antônio de Oliveira Gordo começou a construir o outro prédio e o Tenente Reis terminou o Lauro Sodré novo, dai foi assim, um avanço muito grande para a educação do município, e o Lauro Sodré se tornou a escola sede, essa foi a primeira escola, a mamãe já deu aula no Lauro Sodré, a mãe do prefeito a professora Elinda Ataide de Lima, a professora Maria Maia Paraense, que é a mãe da desembargadora Adair Paraense, foi professora nesse Lauro Sodré, a Professora Jandira Henderson da Silva, então pessoas que trabalharam muito, naquele tempo a educação era exigente demais. Foi muita coisa boa que nós aprendemos que isso ninguém tira da gente, só Deus, mas vai deixar memória, a gente passa o exemplo para os nosso filhos, nossos netos. (NERY, 2010)

No decorrer da construção da história dessa organização escolar, pessoas foram passando por sua estrutura e participando dos acontecimentos ocorridos em seu interior e contribuindo com o sistema de ensino de Moju. Por isso, quando questionada se o Grupo Escolar trouxe benefícios para a educação municipal, a ex -professora Nadir Trindade foi enfática em sua resposta.

Trouxe sim, tanto o antigo grupo quanto $o$ novo. $O$ antigo porque trouxe muito beneficio para o municipio, somente pelo fato de os professores da época se dedicarem e aumentarem o número de educadores no município já foi uma grande vantagem, porque mais de cem por cento dos professores foram formados pelo municipio e continuaram trabalhando lá na escola. (TRINDADE, 2010)

O fato de o Grupo ter formado os quadros profissionais do município é um dado que deixou marcada a presença dessa instituição de ensino, pois, em um sistema social no qual a profissão é o sinônimo de desenvolvimento, esse espaço de formação se mostrou útil qualificando a mão-de-obra mojuense.

Nas entrevistas coletadas junto aos gestores, todos manifestaram unanimemente o sentimento de gratidão por reconhecerem que esta era a única escola existente à época em que eram estudantes. Para eles, o Grupo Escolar foi a base da formação de muitos profissionais como ressalta o Professor Almeida (2010).

A maioria dos profissionais mojuenses estudaram no Lauro Sodré, então o Lauro Sodré foi, assim, um marco da educação no Moju, é uma escola que até hoje dou aula lá, é uma escola que me ajudou a crescer muito, foi lá que eu fiz o meu primário. Agradeço muito ao Lauro Sodré, e acredito que é uma das escolas mais importantes da parte histórica $e$ atual do nosso municipio é a escola Lauro Sodré, por conta que nós professores que hoje estamos atuando com nivel superior, com pós-graduação, fazendo mestrado, nós agradecemos ao Lauro Sodré que foi o pioneiro na educação aqui de Moju na nossa geração.

Se hoje temos profissionais que trabalham aqui, na sociedade, nos órgãos do município, empresários, a base nossa, 
aqui a nossa formação de uma forma muito espetacular foi o Lauro Sodré.

A partir do depoimento do ex-diretor pode-se analisar que o objetivo desse ambiente educativo em Moju foi cumprido, pois, à medida que a instituição de ensino consegue formar novos quadros no ensino primário e os coloca para atuarem na sociedade, a finalidade de preparar a mão-de-obra através do ensino escolar fora atingida.

Com isso pode ser afirmado que o Grupo Escolar foi uma edificação que deu certo, porque, em seu espaço, as metas sociais da educação foram concretizadas. À medida que um ex-estudante é inserido no mercado de trabalho ou atinge outro nível de escolaridade, ele torna real o ideal antes projetado para ele através da instituição de ensino.

\section{Algumas dificuldades enfrentadas du- rante a permanência na instituição escolar}

As situações ocorridas envolvendo os profissionais que atuaram no Grupo Escolar Lauro Sodré foram experiências que marcaram sua permanência na instituição. Assim, resgatar esses episódios é importante para conhecermos as condições em que se dava o trabalho educativo praticado pelos docentes. Como aponta Maria Regina Cardoso Nery, que esclarece que, muitas vezes, não havia condições para o repasse do conhecimento por carência na formação do professor, por isso, alguns se lançaram em busca de certificação em outros níveis de escolaridade, como ocorreu com as professoras Maria Auxiliadora e Regina

A professora acima mencionada representa um exemplo claro das inúmeras tentativas que muitos profissionais faziam para ingressar no ensino superior, mas, pela pouca oportunidade de vagas nas universida- des, a disputa se acirrava. No entanto, além da questão da formação, outros docentes apresentaram diferentes percalços como, por exemplo, a perseguição política, a inexperiência no início da carreira de professor, a falta de matérias para trabalhar, ou seja, mesmo com todas as conquistas os profissionais dos serviços gerais, secretários, diretores sofriam para trabalhar na área da educação.

A dificuldade só foi as perseguições politicas, só isso, o resto foi maravilhoso, o trabalho eu fazia por gosto, eu ganhava 100 horas eu trabalhava de manhã, intermediário, a tarde a noite para mim ter a escola, aqui, na palma da minha mão, se você perguntasse: Onde está um grampo? A Fátima sabia onde estava. Eu me desdobrava não era por causa do dinheiro, mas era por causa do amor ao trabalho, eu queria trabalhar, eu não pensava em dinheiro, a minha maior ganância era de trabalhar. (NERY, 2010)

Ao ser questionado sobre as dificuldades para o exercício de seu trabalho, os docentes, às vezes, faziam uma exaltação do trabalho ao invés de relatar as desventuras ocorridas durante o tempo que exerceram a profissão. Não que não houvesse dificuldades, mas se comparado à satisfação e à realização que sentem por terem desenvolvido bem sua função, as dificuldades que estavam camufladas na falta de recursos didáticos, a pouca valorização do magistério etc., e que eram rotina na vida do profissional da educação, pareciam pequenas, chegando a não ser necessário descrevê-las.

O baixo salário do profissional da educação, outra dificuldade apontada pelos entrevistados, fazia o professor do nível primário ter a jornada de trabalho extensa, não dando a ele condições de desenvolver bem seu profissionalismo e nem ter tempo para se dedicar ao aprimoramento da formação. Essas dificuldades levantadas pelo professor Raimundo Almeida reforçam a análise de que para haver melhoria e qualidade na edu- 
cação o professor tem que ser melhor assistido e mais bem remunerado.

\section{Trabalho docente e gestão no interior do grupo escolar: percalços e desafios}

Ao lermos as entrevistas, observaremos que, desde o ano 1968 até 2008, o trânsito de docentes no Grupo Escolar Lauro Sodré foi muito grande, e que a organização da instituição passou por muitas reformas de acordo com o movimento de mudanças ocorrido pela implantação das legislações educacionais. Baseado nas entrevistas, nota-se que as mudanças ocorridas na instituição foram muitas e pela exposição das docentes elas chegam a confundir o leitor, que pode questionar-se sobre a correspondência dos fatos com as datas sugeridas pelos narradores.

Por ser longo o período de registro histórico educacional, muitas vezes pode haver conflito no ordenamento das informações, o que não nega seu acontecimento, pois segundo Foucault (1996), as condições políticas e econômicas de existência constroem verdades e dependem de quem narra, expõe uma visão dos fatos que foi testemunha, dependendo da posição que este ocupou no tabuleiro das relações sociais.

Nessa mesma linha de pensamento, também Burke (1992, p. 166), diz que: “[As fontes orais] corrigem as outras perspectivas, assim como as outras perspectivas as corrigem". Ao longo do registro da história do Grupo Escolar as diversas formas de fontes se cruzam para contar os acontecimentos vividos no interior da escola.

O pronunciamento dos ex-gestores a respeito do trabalho que desenvolveram na administração da instituição de ensino, envolvido com o processo de municipalização do ensino, indica que o setor educacional seguiu a igual normativa que os setores públicos como a saúde, segurança pública, assistência social, e outros mais, assumiram que Costa (2002) se refere como a municipalização dos recursos, e que no Estado do Pará segundo Corrêa (2000, p.13) visava a aplicação do projeto neoliberal de gestão dos recursos públicos no Estado do Pará. Ou como discorrem Faria e Souza (2004) fazia parte da diretriz governamental de otimização dos recursos, criando condições para maior eficácia, dando maior agilidade e transparência na prestação dos serviços públicos.

Em meio a tantas conjecturas teórico-políticas, a atividade dos profissionais da educação tornou o Grupo Escolar Lauro Sodré uma instituição de referência da educação em Moju. Para tanto os entrevistados ressaltaram a enorme contribuição que eles deram para essa construção, mas também reconheceram o quanto receberam ao estarem presentes envolvidos no processo ensino-aprendizado.

A troca de benefícios adquiridos por meio do trabalho docente possibilitou muitas conquistas para a instituição em cada período histórico de desenvolvimento do município, como deflagram Costa e Corrêa (2010), analisando que houve momentos da história que Moju, por seu potencial em terras e matéria-prima, esteve na rota do desenvolvimento o ensino acompanhou esse movimento de expansão em igual ritmo e o Grupo Escolar Lauro Sodré revelou-se a instituição de ensino que mais cresceu neste cenário.

A participação dessa organização escolar no crescimento educacional e no econômico do município pode ser observada pelos alunos que deixaram a instituição e se lançaram no mercado de trabalho local, dado confirmado pela narrativa da professora Nadir Trindade da Silva ao recordar seus ex-alunos que atualmente ocupam cargos em empresas públicas e privadas, o que demonstra que o trabalho docente teve grande influência na vida dos cidadãos mojuenses. 
Para tanto, havia dificuldades para a concretização das realizações do trabalho no Grupo Escolar, pois, por ser pouco o grau de formação dos docentes, faltava método de ensino, os recursos didáticopedagógicos eram escassos, a infraestrutura do prédio não oferecia condições ao atendimento educacional de qualidade, reflexo da política para o atendimento de metas que não determinava a educação como alvo de investimento, segundo apontam Lara e Maronez (2005), ao analisarem a relevância da educação no contexto do novo modelo globalizado diante das novas metas de gestão na política educacional implementada a partir dos anos 1990.

\section{Conclusão}

Em mais de um século de existência, a primeira instituição de ensino primário de Moju passou por transformações começando por: Grupo Escolar de Moju, Grupo Escolar Lauro Sodré, Escola Estadual de $1^{\circ}$ grau Dr. Lauro Sodré e finalmente Escola Municipalizada de Ensino Fundamental e Médio Lauro Sodré. As mudanças de nome da instituição fazem parte do percurso feito pelo sistema de ensino brasileiro e que o estabelecimento de ensino acompanhou desde o início do século XIX, quando foi fundado, afinado com a política educacional estabelecida pelas diretrizes de Estado.

Vê-se, pois, que o Grupo Escolar Lauro Sodré sempre esteve dedicado à finalidade de ofertar o ensino aos alunos de Moju, de modo a integrá-los ao convívio cívico da cidadania. Ainda que no mesmo espaço, além dos alunos, estiveram presentes gestores, técnicos, professores, auxiliares de serviços gerais, pais e representantes da comunidade externa. Assim, a instituição de ensino se constituiu, também, espaço de relações, conflitos, tensões, manifestações. No interior da escola, conviveram membros das diferentes classes sociais: professores, políticos, operários, agricultores, ribeirinhos, pescadores, comerciantes. Classes que têm interesse dentro do contexto da educação e que, para se fazerem ouvir, articulavam, manipulavam e promoviam manifestações de adesão ou repúdio às medidas oficiais.

É interessante notar que, no bojo do desenvolvimento do processo educacional no Grupo Escolar Lauro Sodré, em que muitas pessoas estiveram envolvidas, muitas manifestações políticas, sociais, artísticas, técnicas, administrativas foram desenvolvidas correspondendo a um padrão ideológico, teórico e cultural que, a cada período histórico, norteou a vida da sociedade e o próprio encaminhamento da educação. A esse respeito é interessante suscitar Braudel (1978, p. 250) quando diz que: "A história — ou melhor, o "destino" de uma cultura é um encadeamento, diríamos em nossa gíria de hoje, uma estrutura dinâmica e de longa duração". Ou seja, os processos construídos no tempo dos Grupos Escolares constituíram padrões culturais de educação que tiveram influência direta na vida da sociedade.

Em meio a todas as situações vividas no interior dessa organização de ensino, sobressaiu o conceito principal de sua existência, que foi ter contribuído com o processo de institucionalização do ensino no município de Moju, construindo ao mesmo tempo as características consolidadas do currículo e possibilitando a solidificação das bases para a formação e trabalho docente.

À medida que esse ambiente de ensino foi fixando as bases da formação no município de Moju, outros fenômenos se desenvolviam simultaneamente a estruturação dessa instituição, particularmente a reprodução dos ideários educacionais voltados à formação do cidadão dotado de capacidade moral e com condi- 
ções para o trabalho, modelo definido pelas estruturas governamentais representativas do Estado e repassado através do currículo oficial.

Nesse sentido, o Grupo Escolar se tornou a estrutura que guardava, abrigava os conteúdos inerentes à formação cultural julgada necessária à vida cidadã. Mas, sozinho, não conseguiria implantar nas mentes dos educandos o currículo que representava. Para tanto, utilizou a mão-de-obra dos profissionais da educação que o próprio sistema de ensino cuidou de formar.
No ambiente interno em que se dinamizava a vida acadêmico-administrativa do Grupo Escolar, embora as regras institucionais forçassem o estabelecimento da ordem ditatorial, os profissionais da educação que nele atuaram conseguiram dar outro direcionamento ao aspecto formativo e administrativo, possibilitando que os princípios democráticos e participativos também fizessem parte de sua constituição histórica.

\section{Referências}

AZANHA, J. M. P. Uma idéia sobre a municipalização do ensino. Estud. av. v. 5, n. 12 São Paulo May/Aug. 1991. Disponível em: <http://www.scielo.br/pdf/ea/v5n12/v5n12a05.pdf> Acesso em: 23 jun. 2017

AUGUSTA, Maria. Entrevista [mai. 2010]. Entrevistador: Renato Pinheiro da Costa. Moju-Pa, 2010. Entrevista Concedida à pesquisa de Dissertação de Mestrado: O Grupo Escolar Lauro Sodré em face da política de expansão do sistema escolar no Estado do Pará: institucionalização, organização curricular e trabalho docente (1968-2008).

AUXÍLIADORA, Maria. Entrevista [mai. 2010]. Entrevistador: Renato Pinheiro da Costa. Moju-Pa, 2010. Entrevista Concedida à pesquisa de Dissertação de Mestrado: O Grupo Escolar Lauro Sodré em face da política de expansão do sistema escolar no Estado do Pará: institucionalização, organização curricular e trabalho docente (19682008)

BELLO, José Luiz de Paiva. Movimento Brasileiro de Alfabetização - MOBRAL: História da Educação no Brasil. Período do Regime Militar Vitória, 1993. Disponível em: <http://www.pedagogiaemfoco.pro.br/heb10a.htm>. Acesso em: 12 maio. 2010.

BRASIL, República Federativa do Brasil, Lei $n^{\circ} 5.692$ de 11 de Agosto de 1971- Disponível em: <http:// www.jusbrasil.com.br/legislacao/128525/lei-de-diretrizes-e-base-de-1971-lei-5692-71>. Acesso em: 13 abr. 2010.

BRASIL, República Federativa do Brasil, Lei $n^{\circ}$ 4.024, de 20 de dezembro de 1961- Disponível em: <http:// www.jusbrasil.com.br/legislacao/108164/lei-de-diretrizes-e-base-de-1961-lei-4024-61>. Acesso em 15 abr. 2010.

BRASIL. Ministério da Educação. IDEB-Índice de Desenvolvimento da Educação Básica, 2009. Disponível em: $<$ http://ideb.inep.gov.br/resultado/>. Acesso em 03 jun. 2010.

BRASIL. Ministério da Educação. Lei de Diretrizes e Bases da Educação nº 9.394, de 20 de dezembro de 1996. Brasília/DF: Câmara dos Deputados, Edições Câmara, 2013. 8 ed.

BRUDEL, Fernand. Escritos sobre a história. São Paulo: Editora Perspectiva 1978

BURKE, Peter. A escrita da história: novas perspectivas. São Paulo: Editora da Universidade Estadual Paulista, 1992.

CORRÊA, P. S. A. A Reforma do Estado nos anos 90 e suas implicações às Políticas Públicas Educacionais na Região Amazônica. Papers do NAEA (UFPA), Universidade Federal do Pará, p. 01-28, 2000. 
EFETIVAÇÃO DAS POLíTICAS CURRICULARES DESENVOLVIDAS PELO GRUPO ESCOLAR LAURO SODRÉ E SEUS DESDOBRAMENTOS SOBRE OS PROCESSOS FORMATIVOS (1968 A 2008)

COSTA, Bruno Lazzarotti Diniz. As mudanças na agenda das políticas no Brasil e os desafios da inovação: O caso das políticas de assistência social a infância e a adolescência. In CARVBALHO, Alisson [et al.] (orgs). Políticas Públicas. Belo Horizonte: Editora UFMG; Proex, 2002.

COSTA, Renato P.; CORREA, P. S. A. Ernestina Pereira Maia: Contribuição com a educação do nível médio de Moju, 2010. Belém, IX Seminário Nacional de Políticas Educacionais e Currículo. PPGED-UFPA, 2010

ESTÁCIO, M. A; NICIDA, L. R. A. História da Educação na Amazônia. Manaus: EDUA; UEA, 2016.

FARIA, L. C. M.; SOUZA, Donaldo Bellode. Reforma do Estado, Descentralização e Municipalização do Ensino no Brasil: A Gestão Política dos Sistemas Públicos de Ensino Pós- LDB 9.394/96. Ensaio. Avaliação e Políticas Públicas em Educação, v. 12, p. 925-944, 2004. Disponível em: <http://www.scielo.br/pdf/ensaio/v12n45/ v12n45a02>. Acesso em: 15 mar. 2010.

FOUCAULT, Michel. A verdade e as formas jurídicas. Rio de Janeiro: Nau editora, 1996.

GORDO, Maria Antônia. Entrevista [mai. 2010]. Entrevistador: Renato Pinheiro da Costa. Moju-Pa, 2010. Entrevista Concedida à pesquisa de Dissertação de Mestrado: O Grupo Escolar Lauro Sodré em face da política de expansão do sistema escolar no Estado do Pará: institucionalização, organização curricular e trabalho docente (1968-2008).

LARA, A. M. B.; MARONEZI, L. F. Z. A reforma do Estado e da educação na década de 1990: Reflexões e repercussões na saúde do professor de ensino fundamental. Ciência, Cuidado \& Saúde, v. 7, p. 404-410, 2008. Disponível em: $\quad<\mathrm{http}: /$ www.estudosdotrabalho.org/anais6seminariodotrabalho/ angelamarabarroslaraelucianefzorzettimaroneze.pdf>. Acesso em: 22 abr. 2010.

LE GOFF, Jacques. História e Memória. Campinas-SP: Editora da UNICAP, 1990.

LOMBARDI, José Claudinei; NASCIMENTO, Isabel Moura (orgs.). Fontes, história e historiografia da educação. São Paulo: Editora Autores Associados, 2004.

MOJU. Escola Municipal de Ensino Fundamental Lauro Sodré. Livro de reuniões. s.e., 1977.

NADIR, Trindade. Entrevista [mai. 2010]. Entrevistador: Renato Pinheiro da Costa. Moju-Pa, 2010. Entrevista Concedida à pesquisa de Dissertação de Mestrado: O Grupo Escolar Lauro Sodré em face da política de expansão do sistema escolar no Estado do Pará: institucionalização, organização curricular e trabalho docente (1968-2008).

NERY, Maria de Fátima. Entrevista [mai. 2010]. Entrevistador: Renato Pinheiro da Costa. Moju-Pa, 2010. Entrevista Concedida à pesquisa de Dissertação de Mestrado: O Grupo Escolar Lauro Sodré em face da política de expansão do sistema escolar no Estado do Pará: institucionalização, organização curricular e trabalho docente (1968-2008).

OLIVEIRA, V. M. F. Educação, memória e histórias de vida: usos da história oral. História Oral (Rio de Janeiro), São Paulo: ABHO, v. 8, n. 1, p. 91-106, 2005.

PARO, Vitor Henrique. A gestão da educação ante as exigências de qualidade e produtividade da escola pública. In: Luiz Heron da Silva. (Org.). A escola cidadã no contexto da globalização. Petrópolis: Vozes, 1998

RIBEIRO, Raimundo Roberto Almeida. Entrevista [mai. 2010]. Entrevistador: Renato Pinheiro da Costa. Moju$\mathrm{Pa}$, 2010. Entrevista Concedida à pesquisa de Dissertação de Mestrado: O Grupo Escolar Lauro Sodré em face da 
política de expansão do sistema escolar no Estado do Pará: institucionalização, organização curricular e trabalho docente (1968-2008)

SILVA, Tomás Tadeu. Documentos de identidade: uma introdução às teorias do currículo. Belo Horizonte: Autêntica, 2010.

Submissão: $26 / 12 / 2016$

Aceite: $25 / 06 / 2017$ 